\title{
Reorganization and plastic changes of the human brain associated with skill learning and expertise
}

\author{
Yongmin Chang * \\ Department of Molecular Medicine and BK21 Plus KNU Biomedical Convergence Program, Kyungpook National University School of Medicine, Daegu, South Korea
}

\section{Edited by:}

Merim Bilalic, University Tübingen,

Germany

Reviewed by:

Marika Berchicci, University of

Rome "Foro Italico," Italy

Ana M. Abreu, Technical University

of Lisbon, Portugal

*Correspondence:

Yongmin Chang, Department of

Molecular Medicine and Radiology,

Kyungpook National University and

Hospital, 50 Samduk-Dong 2Ga,

Chung-Gu, Daegu 700-721,

South Korea

e-mail: ychang@knu.ac.kr
Novel experience and learning new skills are known as modulators of brain function. Advances in non-invasive brain imaging have provided new insight into structural and functional reorganization associated with skill learning and expertise. Especially, significant imaging evidences come from the domains of sports and music. Data from in vivo imaging studies in sports and music have provided vital information on plausible neural substrates contributing to brain reorganization underlying skill acquisition in humans. This mini review will attempt to take a narrow snapshot of imaging findings demonstrating functional and structural plasticity that mediate skill learning and expertise while identifying converging areas of interest and possible avenues for future research.

Keywords: expertise, plasticity, reorganization, neuro imaging, skill learning

\section{INTRODUCTION}

Neuroplasticity, which refers to the brain's ability to change its structure and function, is not an occasional state of the brain, but rather the normal ongoing state of the human brain throughout the life span (Zilles, 1992; Pascual-Leone et al., 2005; Kempermann, 2006; Jancke, 2009). Plastic changes in the human brain lead to brain reorganization that might be demonstrable at the level of behavior, anatomy, and function and down to the cellular and even molecular levels (Kolb and Whishaw, 1998; Kelly and Garavan, 2005; Kleim et al., 2006).

Intentional practice in sports and music has been shown to contribute to acquisition of expertise (Schlaug, 2001; Baker et al., 2003; Hutchinson et al., 2003; Lotze et al., 2003; Calvo-Merino et al., 2005; Ericsson, 2005; Cross et al., 2006; Hung et al., 2007; Nielsen and Cohen, 2008). Acquisition of expertise is accompanied by structural and functional changes of the brain and the advent of brain imaging methods has bolstered the study of these changes in the human brain. Understanding of the neural mechanisms underpinning expertise may provide a basis for determining what types of practice or training are most likely to be beneficial for performance enhancement. This knowledge may also provide a clue as to why some people show improvement at different rates than others or reach much higher levels of achievement. Thus, the study of plastic changes associated with skill learning and expertise in the human brain is one of the most challenging areas of current neuroscience research.

This mini review provides a summary of the in vivo imaging evidence of longitudinal and cross-sectional studies on structural and functional plasticity of the human brain in skill learning and expertise with emphasis on sports and music. In the literature, a cross-sectional approach has been most widely used, and many interesting findings have been reported. However, one of the criticisms of cross-sectional studies is that the differences in brain organization are possibly correlational, and, thus, caution should be used in order not to draw overly strong causal inferences from the cross-sectional data. The concept of plasticity can involve many levels of organization involving molecular, neuronal, or chemical events, and these molecular views of neuroplasticity are beyond the scope of this mini review.

\section{STRUCTURAL NEUROPLASTICITY IN SKILL LEARNING AND EXPERTISE CROSS-SECTIONAL STUDIES}

Cross-sectional imaging studies have demonstrated structural changes of the human brain as a result of experience and learning in sports and music (Amunts et al., 1997; Gaser and Schlaug, 2003; Bangert and Schlaug, 2006; Jacini et al., 2009; Jäncke et al., 2009; Park et al., 2009; Hänggi et al., 2010; Wan and Schlaug, 2010; Wei et al., 2011; Di Paola et al., 2013). For example, Jacini et al. (2009) reported that elite judo players had significantly higher gray matter volume in the frontal lobe, related to motor planning and execution and in regions of the prefrontal cortex, related to working memory and cognitive processes, compared to control subjects. Training induced enlargement in gray matter structure was not limited to brain regions associated with motor planning and execution. When compared to age-matched control subjects, world-class mountain climbers showed significantly larger vermian lobule volumes, possibly associated with highly dexterous hand movements and eye-hand coordination in detection of and correction of visuomotor errors (Di Paola et al., 2013). In the music domain, with measurement of the length of the posterior wall of the precentral gyrus as an estimate of the size of the hand motor area, Amunts et al. (1997) identified substantial structural differences in the hand motor area between professional musicians and non-musicians: in general, the hand motor area was larger in professional musicians than in non-musicians. More importantly, the authors also found that the measures of hand motor area on both hemispheres showed correlation with 
the age of commencement of musical training, implying that earlier musical training results in a stronger impact on structural changes in the hand motor area.

In a study using the voxel-based morphometry (VBM) technique, it was found that skilled golfers (professional and low handicap golfers) had larger gray matter volumes in a frontoparietal network, including premotor and parietal areas (Jäncke et al., 2009). Using the VBM approach, Gaser and Schlaug (2003) reported that professional keyboard players showed differences in gray matter volume in motor, auditory, and visual-spatial brain regions when compared with a matched group of amateur players and non-keyboard players. While the majority of studies on structural neuroplasticity have reported increased gray matter density or volume in expert brains, few studies have reported on the inverse relationship, that is, decreased gray matter volume (Draganski et al., 2006; Hänggi et al., 2010). The several possible reasons for discrepant findings were suggested (Hänggi et al., 2010).

A handful of studies have investigated differences in white matter structure between experts and non-experts, using diffusion tensor imaging (DTI); however, the results have been inconsistent. Using DTI, Jäncke et al. (2009) demonstrated decreased white matter volume and fractional anisotropy (FA) values in several brain structures, including the corticospinal tract (CST), in skilled golfers, compared with less-skilled golfers. Additional evidence for decreased white matter volume and FA values was reported in a study of professional ballet dancers (Hänggi et al., 2010). Contrary to decreased FA values in white matter structures, a very recent study on professional gymnasts showed increased FA values in the bilateral CST in elite gymnasts, possibly in response to long-term gymnastic training as compared to the control subjects (Wang et al., 2013). Inconsistent results have also been reported in the music domain. Imfeld et al. (2009) reported significantly lower FA values in both the left and the right CST in professional musicians compared to non-musicians. However, in another study, pianists who practiced frequently showed higher FA values (Han et al., 2009). Therefore, it appears that acquisition of further evidence will be necessary in order to make a conclusion with regard to whether specific structural changes in white matter can be induced by extensive training.

\section{LONGITUDINAL STUDIES}

To date, only a small number of longitudinal studies have investigated structural brain reorganization as a result of experience and learning. Draganski et al. (2004) investigated the training effect of juggling in inexperienced young jugglers. After a 3-month training period, subjects in the training group showed changes in gray matter density in the intraparietal sulcus and the midtemporal area of visual cortex. The intraparietal sulcus is involved in transforming retinotopic into body centered information necessary to visually control movements. The midtemporal area of visual cortex is a highly specialized brain area for analyzing visual movement information. Of particular interest, the authors also found that after another 3 months without juggling practice, the increase in gray matter density following practice had diminished in all subjects in juggling practice, indicating that structural plasticity is reversible. In a recent study of 60-year old elderly individuals who were able to learn juggling, gray matter changes related to skill acquisition were observed in the midtemporal area of visual cortex similar to that found in young subjects, suggesting that age is not in itself a limiting factor for structural brain plasticity driven by skill learning (Boyke et al., 2008). In a more recent longitudinal study using VBM, in golf novices between the ages of 40 and 60 years, $40 \mathrm{~h}$ of golf training showed an association with gray matter increases in a task-relevant cortical network encompassing sensorimotor regions and areas belonging to the dorsal stream (Bezzola et al., 2011). More importantly, in that study, a strong positive relationship was observed between the increase in gray matter and training intensity in the parieto-occipital junction (POJ), a critical structure of the dorsal stream. A recent review provided evidence of a close association of the POJ with visuomotor processes, particularly in the on-line control and on-line correction of visually guided arm movements (Kravitz et al., 2011). For musical training, Hyde et al. (2009) found that 6-year-old children receiving instrumental musical training for 15 months showed structural change in brain areas such as the precentral gyrus, which is known to be involved in control of playing a musical instrument. Most of these brain areas are part of the cortical motor system; however, structural changes in the auditory system, such as the Heschl gyrus and the corpus callosum, were also observed. These structural changes in the brain showed correlation with performance on various auditory and motor tasks. In addition, in the music domain, the evidence suggests that training-induced plasticity in musicians appears to be most prominent in those who engaged in practice early in childhood (for a review, see Wan and Schlaug, 2010).

\section{FUNCTIONAL NEUROPLASTICITY IN SKILL LEARNING AND EXPERTISE CROSS-SECTIONAL STUDIES}

In motor function, a common finding is the functional enlargement or focused activation of the motor area involved in control of that particular skill (Krings et al., 2000; Pearce et al., 2000; Lotze et al., 2003; Haslinger et al., 2004; Meister et al., 2005; Bangert and Schlaug, 2006). For example, Pearce et al. (2000) reported that the cortical representation of the hand used for playing is larger in professional racquet ball players as compared with novices. In music, one study demonstrated a differential brain adaptation depending on instrument played (Bangert and Schlaug, 2006). More specifically, keyboard players had the left motor area more pronounced as they predominantly use the right hand. In contrast, string players had the right motor area pronounced as the left hand is crucially engaged while playing.

Recent neuroimaging studies have attempted to elucidate the neural activity during action observation in expert brain (CalvoMerino et al., 2006; Pilgramm et al., 2010; Kim et al., 2011). For example, Calvo-Merino et al. (2006) demonstrated the neural bases of motor influences on action observation in expert ballet dancers. They have shown an effect of motor expertise on neural activation within the ventral premotor area and also stronger activation in the inferior parietal and cerebellar regions when observing dance videos, suggesting that the action observation network is more extended than previously suggested (Di Pellegrino et al., 
Table 1 | Imaging evidences for structural and functional plasticity in sports and music.

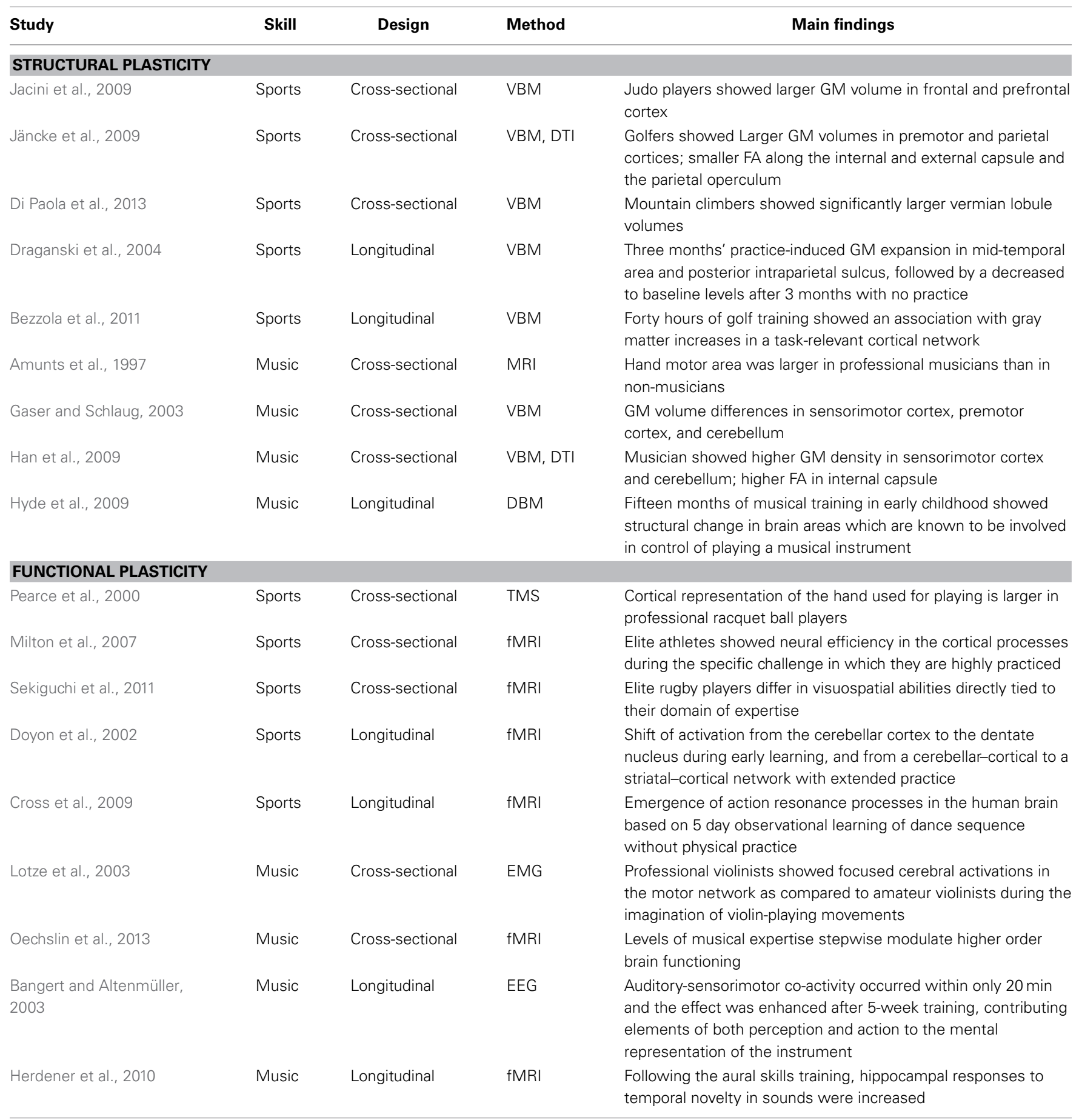

MRI, magnetic resonance imaging; VBM, voxel-based morphometry; GM, gray matter; DTI, diffusion tensor imaging; FA, fractional anisotropy; DBM, Deformation based morphometry; TMS, transcranial magnetic stimulation; $\mathrm{AMRI}$, functional MRI; EMG, Electromyography; EEG, electroencephalography.

1992). For motor planning in expertise, an fMRI study using motor imagery task, which refers to the mental rehearsal of motor acts, demonstrated that the task-related neural networks of expert golfers are focused and efficiently organized, whereas novices have difficulty filtering out irrelevant information (Milton et al., 2007). This finding is consistent with the notion of relative economy (neural efficiency) in the cortical processes of elite athletes during the specific challenge in which they are highly practiced. Similar finding was also observed in professional musicians. Lotze et al. (2003) reported that professional violinists showed focused cerebral activations in the contralateral primary sensorimotor cortex, the bilateral superior parietal lobes, and the ipsilateral anterior 


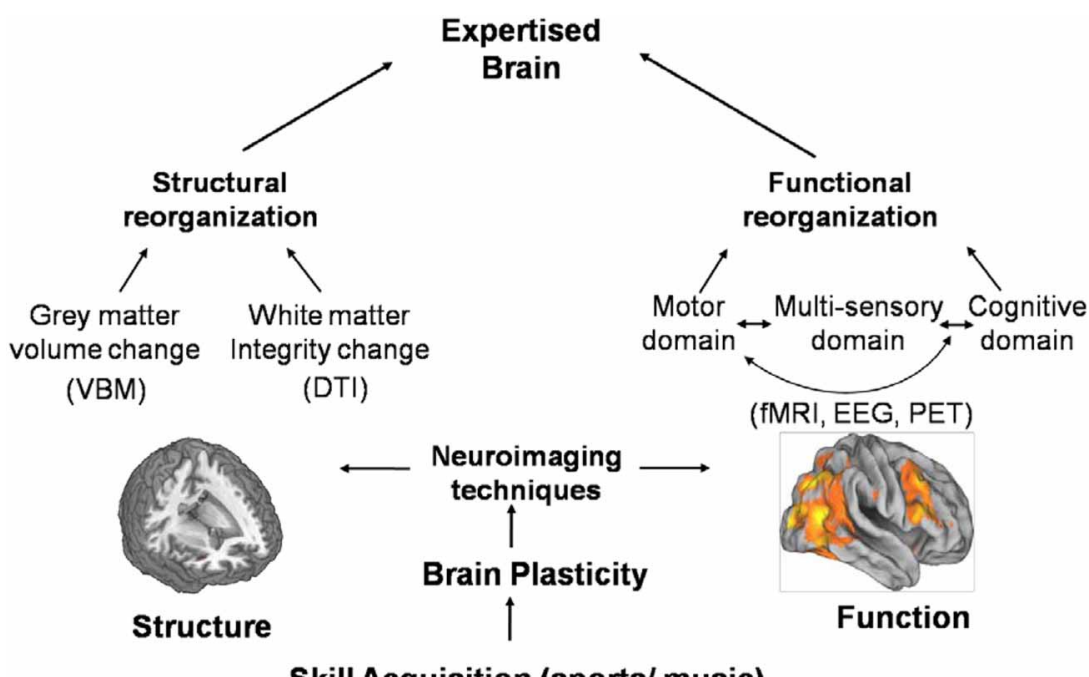

FIGURE 1 | Advances in neuro imaging technique have provided new insights into the neuroplastic changes underlying skill learning and expertise at both structural and functional levels. At structural level, a main finding is increased gray matter volume or density of brain areas associated with skill learning. In functional reorganization, functional imaging evidence has shown that functional neuroplasticity occurs not only in the motor domain but also in cognitive and perceptual domains associated with improved performances. cerebellar hemisphere as compared to amateur violinists during the imagination of violin-playing movements.

As for the visuospatial abilities in sport, evidences seem to suggest that experts differ in visuospatial abilities directly tied to their domain of expertise. For example, one study reported that expert athletes did not differ in their visuospatial capacity than novices as measured on the general visuospatial test (Furley and Memmert, 2010). However, a recent study using fMRI reported quantitative differences in brain activation during visuospatial processing between elite rugby players and novices, indicating the possible existence of a strategy (a bird's eye view) regarding visuospatial cognitive processing for elite rugby players that differs from that of novices (Sekiguchi et al., 2011). More recently, Seo et al. (2012) investigated possible difference in cognitive strategy between archery experts and novices in visuospatial working memory processing. According to their results, archery experts have increased activation in cortical regions important for visuospatial attention and working memory, suggesting that degree of expertise may modulate higher order brain functioning. Taken together, these studies therefore demonstrated that the differences in visuospatial abilities are pronounced in specific domain but those differences did not transfer outside the domain to general visuospatial ability. The possible modulation on function of working memory and attention by expertise was also recently demonstrated in music training. In their multilevel crosssectional study, Oechslin et al. (2013) found evidence for stepwise modulation of brain responses according to level of music expertise in a fronto-temporal network hosting functions of working memory and attention.

\section{LONGITUDINAL STUDIES}

For motor skill acquisition, previous studies using fMRI demonstrated that learning of sequential finger movements initially leads to a functional expansion in the primary motor cortex (M1) and this change in M1 follows more dynamic, rapid changes in the cerebellum, striatum, and other motor-related cortical areas, suggesting an experience-dependent shift of activation from a cerebellar-cortical to a striatal-cortical network with extended practice (Karni et al., 1995; Doyon et al., 2002). In addition, repetition of movements has been suggested to result in motor memories in the primary motor cortex and probably other cortical areas that encode the kinematic details of the practiced movements (Classen et al., 1998; Butefisch et al., 2000; Stefan et al., 2005; Cross et al., 2009). Of particular interest, previous studies have demonstrated that motor memory can also be encoded by action observation and this form of action observation can enhance the effects of motor training on memory encoding, possibly through modulation of intracortical excitatory mechanisms (Stefan et al., 2005; Celnik et al., 2006).

Formation of multisensory connection during motor learning has often been reported in music. In a longitudinal EEG study (Bangert and Altenmüller, 2003), beginning pianists, who had never played an instrument before, were trained on a computer piano over a period of 5 weeks. They listened to short piano melodies, and, after a brief pause, they were then required to replay the melodies using their right hand. After 5 weeks of practice, listening to piano tunes produced additional activity in the sensorimotor regions and in turn, playing on a keyboard produced additional activity in the auditory regions. Therefore, this study nicely demonstrates how dynamic brain adaptations accompany these multisensorimotor learning processes. In another longitudinal study using fMRI (Herdener et al., 2010), the neural responses of musical students in acoustic novelty detection were compared before and after two semesters of intensive aural skills training. Following the training period, hippocampal responses to temporal novelty in sounds were increased 
in music students. A previous study suggested involvement of the hippocampus in various forms of novelty detection in addition to its role in memory (Knight, 1996; Strange et al., 1999). Therefore, this study provides evidence for functional plasticity in the adult hippocampus related to musical training.

\section{CONCLUDING REMARKS}

Over the past decades, advances in human brain imaging have provided new insights into the neuroplastic changes underlying skill learning and expertise in both sports and music (Table 1). These plastic changes can be seen at both structural and functional levels (Figure 1). A main finding of structural plasticity is increased volume and gray matter density of brain areas involved in control of the practiced task. Another major finding in structural plasticity is that experience dependent structural changes can disappear when practicing stops, indicating that structural plasticity is possible in all directions. In musical expertise, one of the distinctive features of structural neuroplasticity is that brain plasticity can be found more clearly if practice starts at a young age. That is, a period might exist, beyond which music-induced structural changes and learning effects are less pronounced. Unfortunately, such studies on a sensitive period are missing in the sport domain.

In functional reorganization, a common finding is the functional enlargement or focused activation of the motor area involved in control of that particular skill. In addition, because expert performance is mediated by cognitive and perceptual motor skills, functional imaging evidence has shown that functional neuroplasticity occurs not only in the motor domain but also in cognitive and perceptual domains associated with improved performances. Furthermore, in music, evidence has demonstrated a strong coupling of sensorimotor and auditory processing for music expertise. Practice in playing a music instrument involves constant improvement of complex sensory-motor coordination through repeated execution of motor activities under the controlled monitoring of the auditory system.

Despite accumulation of significant imaging evidence, as discussed in the current mini-review, understanding of mechanisms underlying these plastic changes is still far from completewhich opens a broad avenue for future research. For example, neuroplasticity can be traced to cellular and molecular levels, and, thus, one of the main challenges is linking human brain imaging findings to the underlying molecular events. Because the poor specificity of macroscopic MR imaging signals largely precludes molecular information, other non-invasive approaches would be needed. Of these methods, molecular imaging using positron emission tomography (PET) is a good candidate. Although there is still a lack of prospective studies on plasticity, integration of PET into MRI with simultaneous recordings of molecular and hemodynamic brain responses opens new and promising prospects for the future (Judenhofer et al., 2008). Another challenge for the understanding of neural mechanisms underlying plastic changes is time scale of neural activity, because the temporal resolution of $\mathrm{fMRI}$ in the order of seconds is approximately three orders of magnitude away from the time scale of neural events in milliseconds order. Therefore, for measurement of brain activity on a time scale of neuronal activity and for assessment of specific neurophysiological events in human, combined fMRI with non-invasive electrophysiological methods such as electroencephalography (EEG) would be beneficial for simultaneous measurement of neuronal and neural brain responses. Combined EEG and fMRI studies can thus take advantage of both, the good spatial resolution of fMRI and the good temporal resolution of EEG (Thees et al., 2002; Debener et al., 2005).

\section{ACKNOWLEDGMENTS}

This study was supported by a grant of the Korean Health Technology R \& D Project, Ministry for Health, Welfare, and Family Affairs, Republic of Korea (A092106).

\section{REFERENCES}

Amunts, K., Schlaug, G., Jancke, L., Steinmetz, H., Schleicher, A., Dabringhaus, A., et al. (1997). Motor cortex and hand motor skills: structural compliance in the human brain. Hum. Brain Mapp. 5, 206-215. doi: 10.1002/(SICI)10970193(1997)5:3\%3C206::AID-HBM5\%3E3.0.CO;2-7

Baker, J., Horton, S., Robertson-Wilson, J., and Wall, M. (2003). Nurturing sport expertise: factors influencing the development of elite athlete. J. Sports Sci. Med. 2, 1-9.

Bangert, M., and Altenmüller, E. (2003). Mapping perception to action in piano practice: a longitudinal DC-EEG study. BMC Neurosci. 4:26. doi: 10.1186/14712202-4-26

Bangert, M., and Schlaug, G. (2006). Specialization of the specialized in features of external human brain morphology. Eur. J. Neurosci. 24, 1832-1834. doi: 10.1111/j.1460-9568.2006.05031.x

Bezzola, L., Merillat, S., Gaser, C., and Jancke, L. (2011). Training-induced neural plasticity in golf novices. J. Neurosci. 31, 12444-12448 doi: 10.1523/JNEUROSCI.1996-11.2011

Boyke, J., Driemeyer, J., Gaser, C., Buchel, C., and May, A. (2008). Traininginduced brain structure changes in the elderly. J. Neurosci. 28, 7031-7035. doi: 10.1523/JNEUROSCI.0742-08.2008

Butefisch, C. M., Davis, B. C.,Wise, S. P., Sawaki, L., Kopylev, L., Classen, J., et al. (2000). Mechanisms of use-dependent plasticity in the human motor cortex. Proc. Natl. Acad. Sci. U.S.A. 97, 3661-3665. doi: 10.1073/pnas.97. 7.3661

Calvo-Merino, B., Glaser, D. E., Grezes, J., Passingham, R. E. and Haggard, P. (2005). Action observation and acquired motor skills: an FMRI study with expert dancers. Cereb. Cortex 15, 1243-1249. doi: 10.1093/cercor/ bhi007

Calvo-Merino, B., Gre'zes, J., Glaser, D. E., Passingham, R. E., and Haggard, P. (2006). Seeing or doing? Influence of visual and motor familiarity in action observation. Curr. Biol 16, 1905-1910. doi: 10.1016/j.cub.2006.07.065

Celnik, P., Stefan, K., Hummel, F., Duque, J., Classen, J. and Cohen, L. G. (2006). Encoding a motor memory in the older adult by action observation. Neuroimage 29, 677-684. doi: 10.1016/j.neuroimage.2005.07.039

Classen, J., Liepert, J.,Wise, S. P., Hallett, M. and Cohen, L. G. (1998). Rapid plasticity of human cortical movement representation induced by practice. J. Neurophysiol. 79,1117-1123.

Cross, E. S., Hamilton, A. F. and Grafton, S. T. (2006). Building a motor simulation de novo: observation of dance by dancers. Neuroimage 31, 1257-1267. doi: 10.1016/j.neuroimage.2006.01.033

Cross, E. S., Kraemer, D. J., Hamilton, A. F., Kelley, W. M., and Grafton, S. T. (2009). Sensitivity of the action observation network to physical and observational learning. Cereb. Cortex 19,315-326 doi: 10.1093/cercor/bhn083

Debener, S., Ullsperger, M., Siegel, M., Fiehler, K., von Cramon, D. Y., and Engel, A. K. (2005). Trial-by-trial coupling of concurrent electroencephalogram and functional magnetic resonance imaging identifies the dynamics of performance monitoring. J. Neurosci. 25,11730-11737. doi: 10.1523/JNEUROSCI.328605.2005

Di Paola, M., Caltagirone, C., and Petrosini, L. (2013). Prolonged rock climbing activity induces structural changes in cerebellum and parietal lobe. Hum. Brain Mapp. 34, 2707-2714. doi: 10.1002/hbm.22095 
Di Pellegrino, G., Fadiga, L., and Gallese, V. (1992). Understanding motor events: a neurophysiological study. Exp. Brain Res. 91, 176-180. doi: 10.1007/BF00 230027

Doyon, J., Song, A. W., Karni, A., Lalonde, F., Adams, M. M., and Ungerleider, L. G. (2002). Experience-dependent changes in cerebellar contributions to motor sequence learning. Proc. Natl. Acad. Sci. U.S.A. 99,1017-1022. doi: 10.1073/pnas.022615199

Draganski, B., Gaser, C., Busch, V., Schuierer, G., Bogdahn, U., and May, A. (2004). Neuroplasticity: changes in grey matter induced by training. Nature 427, 311-312. doi: 10.1038/427311a

Draganski, B., Gaser, C., Kempermann, G., Kuhn, H. G., Winkler, J., Buchel, C., et al. (2006). Temporal and spatial dynamics of brain structure changes during extensive learning. J. Neurosci. 26,6314-6317. doi: 10.1523/JNEUROSCI.462805.2006

Ericsson, K. A. (2005). Recent advances in expertise research. Appl. Cogn. Psychol. 19, 233-241. doi: 10.1002/acp.1111

Furley, P., and Memmert, D. (2010). Differences in spatial working memory as a function of team sports expertise: the Corsi Block-tapping task in sport psychological assessment. Percept. Mot. Skills110, 801-808. doi: 10.2466/pms.110.3.801-808

Gaser, C., and Schlaug, G. (2003). Brain structures differ between musicians and nonmusicians. J. Neurosci. 23, 9240-9245.

Hänggi, J., Koeneke, S., Bezzola, L., and Jäncke, L. (2010). Structural neuroplasticity in the sensorimotor network of professional female ballet dancers. Hum. Brain Mapp. 31, 1196-1206. doi: 10.1002/hbm.20928

Han, Y., Yang, H., Lv, Y. T., Zhu, C. Z., He, Y., Tang, H. H., et al. (2009). Gray matter density and white matter integrity in pianists' brain: a combined structural and diffusion tensor MRI study. Neurosci. Lett. 459, 3-6. doi: 10.1016/j.neulet.2008.07.056

Haslinger, B., Erhard, P., Altenmuller, E., Hennenlotter, A., Schwaiger, M., Grafin von Einsiedel, H., et al. (2004). Reduced recruitment of motor association areas during bimanual coordination in concert pianists. Hum. Brain Mapp. 22, 206-215. doi: 10.1002/hbm.20028

Herdener, M., Esposito, F., di Salle, F., Boller, C., Hilti, C. C., Habermeyer, B., et al. (2010). Musical training induces functional plasticity in human hippocampus. J. Neurosci. 30, 1377-84. doi: 10.1523/JNEUROSCI.4513-09.2010

Hung, T., Haufler, A., Lo, L., Mayer-Kress, G., and Hatfield, B. (2007). Visuomotor expertise and dimensional complexity of cerebral cortical activity. Med. Sci. Sports Exerc. 40, 752-759. doi: 10.1249/MSS.0b013e318162c49d

Hutchinson, S., Lee, L. H., Gaab, N., and Schlaug, G. (2003). Cerebellar volume of musicians. Cereb. Cortex 13, 943-949. doi: 10.1093/cercor/13.9.943

Hyde, K. L., Lerch, J., Norton, A., Forgeard, M., Winner, E., Evans, A. C., et al. (2009). Musical training shapes structural brain development. J. Neurosci. 29, 3019-3025. doi: 10.1523/JNEUROSCI.5118-08.2009

Imfeld, A., Oechslin, M. S., Meyer, M., Loenneker, T., and Jancke, L. (2009). White matter plasticity in the corticospinal tract of musicians: A diffusion tensor imaging study. Neuroimage 46, 600-607. doi: 10.1016/j.neuroimage.2009. 02.025

Jacini, W. F., Cannonieri, G. C., Fernandes, P. T., Bonilha, L., Cendes, F., and Li, L. M. (2009). Can exercise shape your brain? Cortical differences associated with judo practice. J. Sci. Med. Sport 12, 688-690. doi: 10.1016/j.jsams.2008. 11.004

Jancke, L. (2009). The plastic human brain. Restor. Neurol. Neurosci. 27, 521-538. doi: 10.3233/RNN-2009-0519

Jäncke, L., Koeneke, S., Hoppe, A., Rominger, C., and Hänggi, J. (2009). The architecture of the golfer's brain. PLoS ONE 4:e4785. doi: 10.1371/journal.pone. 0004785

Judenhofer, M. S., Wehrl, H. F., Newport, D. F., Catana, C., Siegel, S. B., Becker, M., et al. (2008). Simultaneous PET-MRI: a new approach for functional and morphological imaging. Nat. Med. 14, 459-465. doi: 10.1038/nm1700

Karni, A., Meyer, G., Jezzard, P., Adams, M. M., Turner, R. and Ungerleider, L. G. (1995). Functional MRI evidence for adult motor cortex plasticity during motor skill learning. Nature 377, 155-158. doi: 10.1038/377155a0

Kelly, A. M. C., and Garavan, H. (2005). Human functional neuroimaging of brain changes associated with practice. Cereb. Cortex 15, 1089-1102. doi: 10.1093/cercor/bhi005

Kempermann, G. (2006). “Adult neurogenesis," in In Lifespan Development and the Brain eds P. B. Baltes, P. A. Reuter-Lorenz, and F. Rösler (Cambridge University Press), 82-107. doi: 10.1017/CBO9780511499722.006
Kim, Y. T., Seo, J. H., Song, H. J., Yoo, D. S., Lee, H. J., Lee, J., et al. (2011). Neural correlates related to action observation in expert archers. Behav. Brain Res. 223, 342-347. doi: 10.1016/j.bbr.2011.04.053

Kleim, J. A., Chan, S., Pringle, E., Schallert, K., Procaccio, V., Jimenez, R., et al. (2006). BDNF val66met polymorphism is associated with modified experiencedependent plasticity in human motor cortex. Nat. Neurosci. 9, 735-737. doi: 10.1038/nn 1699

Knight, R. (1996). Contribution of human hippocampal region to novelty detection. Nature 383, 256-259. doi: 10.1038/383256a0

Kolb, B., and Whishaw, I. Q. (1998). Brain plasticity and behavior. Annu. Rev. Psychol. 49, 43-64. doi: 10.1146/annurev.psych.49.1.43

Kravitz, D. J., Saleem, K. S., Baker, C. I., and Mishkin, M. (2011). A new neural framework for visuospatial processing. Nat. Rev. Neurosci. 12, 217-230. doi: $10.1038 / \mathrm{nrn} 3008$

Krings, T., Topper, R., Foltys, H., Erberich, S., Sparing, R., Willmes, K., et al. (2000). Cortical activation patterns during complex motor tasks in piano players and control subjects. a functional magnetic resonance imaging study. Neurosci. Lett. 278, 189-193. doi: 10.1016/S0304-3940(99)00930-1

Lotze, M., Scheler, G., Tan, H. R., Braun, C., and Birbaumer, N. (2003). The musician's brain: Functional imaging of amateurs and professionals during performance and imagery. Neuroimage 20, 1817-1829. doi: 10.1016/j.neuroimage.2003.07.018

Meister, I., Krings, T., Foltys, H., Boroojerdi, B., Muller, M., Topper, R., et al. (2005). Effects of long-term practice and task complexity in musicians and nonmusicians performing simple and complex motor tasks: implications for cortical motor organization. Hum. Brain Mapp. 25, 345-352. doi: 10.1002/ hbm. 20112

Milton, J., Solodkin, A., Hluštík, P., and Small, S. L. (2007). The mind of expert motor performance is cool and focused. Neuroimage 35, 804-813. doi: 10.1016/j.neuroimage.2007.01.003

Nielsen, J. B., and Cohen, L. G. (2008). The Olympic brain. Does corticospinal plasticity play a role in acquisition of skills required for high performance sports? J. Physiol. 586, 65-70. doi: 10.1113/jphysiol.2007.142661

Oechslin, M. S., Van De Ville, D., Lazeyras, F., Hauert, C. A., and James, C. E. (2013). Degree of musical expertise modulates higher order brain functioning. Cereb. Cortex 23, 2213-2224. doi: 10.1093/cercor/bhs206

Park, I. S., Lee, K. J., Han, J. W., Lee, N. J., Lee, W. T., Park, K. A., et al. (2009). Experience-dependent plasticity of cerebellar vermis in basketball players. Cerebellum 8, 334-339. doi: 10.1007/s12311-009-0100-1

Pascual-Leone, A., Amedi, A., Fregni, F., and Merabet, L. B. (2005). The plastic human brain cortex. Annu. Rev. Neurosci. 28, 377-401. doi: 10.1146/annurev.neuro.27.070203.144216

Pearce, A. J., Thickbroom, G. W., Byrnes, M. L., and Mastaglia, F. L. (2000) Functional reorganisation of the corticomotor projection to the hand in skilled racquet players. Exp. Brain Res. 130, 238-243. doi: 10.1007/s0022199 00236

Pilgramm, S., Lorey, B., Stark, R., Munzert, J., Vaitl, D., and Zentgraf, K. (2010). Differential activation of the lateral premotor cortex during action observation. BMC Neurosci. 11:89. doi: 10.1186/1471-2202-11-89

Schlaug, G. (2001). The brain of musicians. A model for functional and structural adaptation. Ann. N.Y. Acad. Sci. 930, 281-299. doi: 10.1111/j.17496632.2001.tb05739.x

Sekiguchi, A., Yokoyama, S., Kasahara, S., Yomogida, Y., Takeuchi, H., Ogawa, T., et al. (2011). Neural bases of a specific strategy for visuospatial processing in rugby players. Med. Sci. Sports Exerc. 43, 1857-1862. doi: 10.1249/MSS.0b013e31821920f3

Seo, J., Kim, Y. T., Song, H. J., Lee, H. J., Lee, J., Jung, T. D., et al. (2012). Stronger activation and deactivation in archery experts for differential cognitive strategy in visuospatial working memory processing. Behav. Brain Res. 229,185-193. doi: 10.1016/j.bbr.2012.01.019

Stefan, K., Cohen, L. G., Duque, J., Mazzocchio, R., Celnik, P., Sawaki, L., et al. (2005). Formation of a motor memory by action observation. J. Neurosci. 25, 9339-9346. doi: 10.1523/JNEUROSCI.228205.2005

Strange, B. A., Fletcher, P. C., Henson, R. N., Friston, K. J., and Dolan, R. J. (1999). Segregating the functions of human hippocampus. Proc. Natl. Acad. Sci. U.S.A. 96, 4034-4039. doi: 10.1073/pnas.96.7.4034

Thees, S., Blankenburg, F., Taskin, B., Curio, G., and Villringer, A. (2002). Dipole source localization and fMRI of simultaneously recorded data applied to 
somatosensory categorization. Neuroimage 18, 707-719. doi: 10.1016/S10538119(02)00054-X

Wan, C. Y., and Schlaug, G. (2010). Music making as a tool for promoting brain plasticity across the life span. Neuroscientist 16, 566-577. doi: $10.1177 / 1073858410377805$

Wang, B., Fan, Y., Lu, M., Li, S., Song, Z., Peng, X., et al. (2013). Brain anatomical networks in world class gymnasts: A DTI tractography study. Neuroimage 65, 476-487. doi: 10.1016/j.neuroimage.2012. 10.007

Wei, G., Zhang, Y., Jiang, T., and Luo, J. (2011). Increased cortical thickness in sports experts: a comparison of diving players with the controls. PLoS ONE 6:e17112. doi: 10.1371/journal.pone.0017112

Zilles, K. (1992). Neuronal plasticity as an adaptive property of the central nervous system. Ann. Anat. 174, 383-391. doi: 10.1016/S0940-9602(11) $80255-4$
Conflict of Interest Statement: The author declares that the research was conducted in the absence of any commercial or financial relationships that could be construed as a potential conflict of interest.

Received: 18 July 2013; accepted: 17 January 2014; published online: 04 February 2014. Citation: Chang Y (2014) Reorganization and plastic changes of the human brain associated with skill learning and expertise. Front. Hum. Neurosci. 8:35. doi: 10.3389/ fnhum.2014.00035

This article was submitted to the journal Frontiers in Human Neuroscience.

Copyright $\odot 2014$ Chang. This is an open-access article distributed under the terms of the Creative Commons Attribution License (CC BY). The use, distribution or reproduction in other forums is permitted, provided the original author(s) or licensor are credited and that the original publication in this journal is cited, in accordance with accepted academic practice. No use, distribution or reproduction is permitted which does not comply with these terms. 